Research Paper

\title{
Prognostic Value of Proliferation Markers: Immunohistochemical Ki-67 Expression and Cytometric S-Phase Fraction of Women with Breast Cancer in Libya
}

\section{Eramah Ermiah ${ }^{1,2}{ }^{\varpi}$, Abdelbaset Buhmeida ${ }^{3}$, Fathi Abdalla ${ }^{4}$, Ben Romdhane Khaled ${ }^{5}$, Nada Salem ${ }^{6}$, Seppo Pyrhönen ${ }^{1}$ and Yrjö Collan ${ }^{7}$}

1. Department of Oncology and Radiotherapy, University of Turku and Turku University Hospital, Finland;

2. Department of Oncology, National Cancer Institute, Sabratha, Libya;

3. Center of Excellence in Genomic Medicine Research, King Abdul-Aziz University, Jeddah, Saudi Arabia;

4. Department of Pathology, Misurata Cancer Institute, Libya;

5. Department of Pathology, Salah Azaiz Cancer Institute, Tunis, Tunisia;

6. Department of Biochemistry, King Abdul-Aziz University, Jeddah, Saudi Arabia;

7. Department of Pathology, University of Turku, Turku, Finland.

$\triangle$ Corresponding author: Dr. Eramah Ermiah, MD, Department of Oncology, National Cancer Institute, Sabratha, Libya. Alfassi Street, Alzawia city, Libya. Phone number: +218-913792106. Email: eelramah@yahoo.com

(C) Ivyspring International Publisher. This is an open-access article distributed under the terms of the Creative Commons License (http://creativecommons.org/ licenses/by-nc-nd/3.0/). Reproduction is permitted for personal, noncommercial use, provided that the article is in whole, unmodified, and properly cited.

Received: 2012.07.29; Accepted: 2012.09.01; Published: 2012.10.01

\begin{abstract}
Background: We evaluated the association of the immunohistochemical Ki-67 expression, and S-phase fraction with clinicopathological variables and patient outcome.

Patients and methods: Histological samples from 100 primary Libyan breast carcinoma patients were retrospectively studied with monoclonal antibody to Ki-67. S-phase fraction was determined by DNA image cytometry.

Results: The median $\mathrm{Ki}-67$ percentage for all tumors was $27.5 \%$, ranging from I to $80 \%$ and the median S-phase fraction (SPF) was II\%, ranging from 0 to $62 \%$. Tumors with high $\mathrm{Ki}-67$ expression were found in $76 \%$ of patients and with high SPF values in $56 \%$. Ki-67 expression was more frequent in tumors with high SPF than low SPF. High Ki-67 and high SPF were associated with advanced stages, poor differentiation of tumors, positive lymph nodes, and distant metastasis. The Ki-67 was associated with hormone receptor negative tumors. The SPF was higher in young patients ( $<50$ years) than in older patients. In the overall population (median follow-up 49 months), patients with high Ki-67 and high SPF had shorter survival time and predicted recurrence than patients with low Ki-67 and low SPF. In a Cox multivariate analysis, high SPF $(p=0.007)$, hormonal status $(p=0.00 \mathrm{I})$ and clinical stage $(p=0.005)$ were independent predictors of disease-specific survival. The Ki-67 $(p=0.065)$ in borderline significance proved to be independent predictor of disease-free survival. The SPF showed more statistically significance with a high grade of malignancy and survival time than Ki-67.

Conclusions: The SPF value is useful cell proliferation marker to assess tumor prognosis. These markers may reflect the aggressive behavior of Libyan breast cancer and predict of the recurrence. It is therefore important to take these markers into consideration to select a high risk subgroup of the patients for intensive treatment.
\end{abstract}

Key words: Ki-67 expression, S-phase fraction, Libyan female breast cancer, prognosis 


\section{INTRODUCTION}

In Libya, the incidence of breast cancer is 18.8 new cases per 100,000 women per year [1]. The patients often present with advanced disease, have early disease recurrence and are associated with high mortality $[1,2]$. It is also important to realize that patients in Libya have a mean age of 46 years, showing that premenopausal cancers are more common than in Europe. The age pattern is identical with the ages of breast cancer patients in Africa or Middle East and North Africa (MENA) region [3-5].

Several clinical and pathological variables are useful for assessing the prognosis of breast cancer patients. Therefore, an active search is going on for powerful new prognostic and predictive tools for identifying a high-risk patient who would benefit from individually tailored treatment options [6]. As a part of this ongoing search, we focus on the immunostaining analysis of $\mathrm{Ki}-67$ and quantitatively measurable DNA content (which allows the evaluation of SPF) [7-9]. These biological markers have an important role as independent prognostic parameters in relation to the traditional clinicopathological variables which lead to the determination of tumour prognosis.

The proliferative rates of tumor have been evaluated in an attempt to correlate them with prognosis. These putative markers include immunohistochemical (IHC) analysis using antibodies directed against proliferation antigens such as Ki-67, cytometric S-phase fraction (SPF), proliferating-cell nuclear antigen, thymidine labeling index and mitotic index [10-13].

$\mathrm{Ki}-67$ antigen is one of several cell-cycle regulating proteins which can be determined by Immunohistochemistry [14]. The Ki-67 antibody reacts with a nuclear non-histone protein of $395 \mathrm{KD}$ that is express in all active phases of the cell cycle, except the G0 [15].

The proliferation biomarker Ki-67 is considered to be a prognostic factor for breast cancer has been investigated in several studies $[7,8]$. The association between a high Ki-67 labelling index, poor differentiation of tumors and large tumor size in breast carcinoma were demonstrated in many studies $[7,16]$. Various studies have shown correlations between Ki-67 and overall survival and disease-free survival, with an increased risk of recurrence in patients with a high Ki-67 [17, 18].

The measurement estimates the fraction of cells in the $S$ phase (S phase fraction), which reflects proliferative activity. Several studies observed the prognostic value of SPF in breast cancer [19-21]. High SPF was significantly associated with advanced stage, large pathological tumor size, lymph node involvement, poor differentiation of tumors and low survival in the patients with breast carcinoma $[10,11]$.

Covering studies on proliferation markers in these populations (Libyans) have not been made. In this study we try to compare Ki-67 and SPF (S-phase fraction) both of which has been used as proliferation markers for clinical decision making.

The purpose of this study is to study the association between Ki-67 expression and S-phase fraction value with several clinicopathological variables and patient outcome in Libyan breast cancer.

\section{PATIENTS AND METHODS}

\section{Clinicopathological data}

The study group consisted of 100 women diagnosed with breast cancer at the National Cancer Institute, Sabratha, Libya between February 2000 and December 2007. All clinicopathological and clinical data were collected from the patient's files. The collected data included age, menopausal status, family history, hormonal status, histological type, tumor size, lymph node status, tumor stage, histological grade, treatment type, and medical follow up. The eligibility criteria for patients included the availability of frozen samples (before any treatment) for analysis of immunostaining and image cytometry, and accurate data of follow up. Tumour staging of breast carcinoma was evaluated according to TNM classification [22]. The hormone receptor status of the tumors was tested at the time of surgery. Monoclonal antibody was used for determination of hormone receptors. Interpretation was done with Allred score method [23]. The details of clinicopathological variables are shown in Table 1. The mean age of the patients was 43 (range, 20-80). The series comprised 81 invasive ductal carcinomas and 19 breast carcinomas of other histological types. Tumors were positive for estrogen and progesterone receptors in 67 and 55 patients, respectively. Tumors were negative for estrogen and progesterone receptors in 33 and 45 patients, respectively.

\section{Treatment and Follow up data}

Seventy three percent of patients were treated by modified radical mastectomy and axillary dissection, 14 patients received neoadjvant chemotherapy with modified radical mastectomy and axillary lymph node dissection. Lumpectomy was done in two patients, and simple mastectomy in one patient. No surgical intervention was done for 10 patients with metastasis at time of diagnosis (diagnosis with core biopsy). 
The following treatment guidelines were followed at our institute. Adjuvant and neoadjvant chemotherapy with anthracycline was given to 79 patients while 14 patients received combined chemotherapy based on anthracycline and taxans, and 2 patients received chemotherapy regime based on $\mathrm{CMF}$ [cyclophosphamide, methotrexate and 5- FU]. No chemotherapy was given to 3 patients with early stage, and 2 patients were unfit to receive chemotherapy. Hormonal treatment (tamoxifen) was given to 67 hormone receptor positive patients. Axillary radiotherapy was given to node- positive patients $(\mathrm{n}=$ 80).

The patients were followed-up until death or to the end of the observation period (until October 2010). The median follow-up duration was 49 months (range, 3-113 months). The patients were seen at 3-6 month intervals. The bone isotope scan, and chest, and abdominopelvic CT scan were performed every 6-12 months.

Table I: Clinicopathological variables of 100 patients with breast cancer.

\begin{tabular}{|c|c|c|}
\hline \multicolumn{2}{|c|}{ Clinicopathological variables } & \multirow{2}{*}{$\begin{array}{l}\begin{array}{l}\text { Number of } \\
\text { patients }\end{array} \\
71\end{array}$} \\
\hline Age & $<50$ & \\
\hline & $\geq 50$ & 29 \\
\hline \multirow[t]{2}{*}{ Menopausal status } & Premenopausal & 59 \\
\hline & Postmenopausal & 41 \\
\hline \multirow[t]{2}{*}{ Hormonal status (ER) } & Positive & 67 \\
\hline & Negative & 33 \\
\hline \multirow[t]{2}{*}{ Hormonal status (PR) } & Positive & 55 \\
\hline & Negative & 45 \\
\hline \multirow[t]{2}{*}{ Histopathology type } & IDC & 81 \\
\hline & Other types & 19 \\
\hline \multirow[t]{3}{*}{ Tumor size } & $<2 \mathrm{~cm}$ & 4 \\
\hline & $2-5 \mathrm{~cm}$ & 32 \\
\hline & $>5 \mathrm{~cm}$ & 64 \\
\hline \multirow[t]{2}{*}{ Lymph node status* } & Positive & 80 \\
\hline & Negative & 18 \\
\hline \multirow[t]{3}{*}{ Histological grade } & Grade 1 & 19 \\
\hline & Grade 2 & 52 \\
\hline & Grade 3 & 29 \\
\hline \multirow[t]{4}{*}{ Clinical stage } & Stage 1 & 6 \\
\hline & Stage 2 & 27 \\
\hline & Stage 2 & 57 \\
\hline & Stage 4 & 10 \\
\hline \multirow[t]{2}{*}{ Metastases at diagnosis } & M0 & 90 \\
\hline & M1 & 10 \\
\hline
\end{tabular}

* 98 patients had lymph node status histologically evaluated
Disease free survival (DFS) was defined as the fraction of patients without disease after surgery at various points of follow-up. Disease specific survival (DSS) was defined as the percentage of patients alive at various points of follow-up with other than breast cancer deaths excluded.

At the end of follow up period (mean: 52 months), 62 of patients were alive, 35 had experienced disease recurrence, and 38 had died of breast cancer.

\section{Immunohistochemical staining}

Ki-67 immunostaining was performed for all specimens using tissues obtained before treatment. Formalin fixed, paraffin embedded tissues were cut into sections of $3 \mu \mathrm{m}$. The cutting sections were de-waxed in xylene, rehydrated in graded ethanol. Novocastra Peroxidase bloke (3\% hydrogen peroxide) was used to neutralize endogenous peroxidase activity of the samples for 5 minutes. Ki-67 staining was carried out by mouse monoclonal antibody (Anti Ki-67: Clone NCL-L-KI67-MM1, Novocastra Laboratories, Newcastle Upon-Tyne, UK) at a 1:200 dilution and the samples were incubated for 30 minutes at room temperature. To reveal the binding of primary antibody by peroxidase staining, the substrate/chromogen, 3, 3-diaminobenzidine (DAP), prepared from Novocastra DAP Chromogen and NovaLink DAP Substrate Buffer (Polymer) was used and the samples were incubated for 30 minutes. Finally, the section were counterstained with hematoxylin, dehydrated, cleared, and the sections were mounted for examination.

\section{Staining assessment}

All slides were evaluated without knowledge of the patient's outcome. The slides were examined by one pathologist (B.K) in a Nikon microscope (Eclipse E 600; Japan). Malignant cells with nuclear staining were considered to be positive. Ki-67 expression was counted as a percentage. The percentage was determined by the number of Ki-67 positive cells among the total number of counted tumor cells. A minimum of 500 cells were counted in hot spots per slide. A cut point of $10 \%$ was used to distinguish between the categories of low and high proliferative tumors [24, 25], because it provided the best prognosis prediction results in this study. Laboratory work for Ki-67 immunostaining was done at the Department of $\mathrm{Pa}$ thology, Salah Azaiz Cancer Institute, Tunis, Tunisia.

\section{Static image DNA cytometery}

Image cytometric analysis was performed for all the patients on frozen samples obtained at time of surgery. Nuclei were isolated from 30 micrometer 
thick paraffin sections after xylene treatment and digestion with proteolytic enzymes according to the method described by Hedley et al [26].

Feulgen stain was applied according to the Gaub's et al method [27]. The intensity of Feulgen staining was measured using a computer-assisted image analysis cytometric system AHRENS ICM (designed and produced by Olaf Ahrens Messtechnische Beratung, Bargteheide/Hamburg, Germany) with a Nikon microscope (Eclipse E 400; Japan).

The field of view from the CCD camera (JAI DSP surveillance, CV-S 3200/3300) was stored in image memory at a resolution of 736 by 560 pixels. The image was produced by a plan objective (Nikon; $\times 40$, numerical aperture 0.65 ) and the measurements were made from that image. Prior to each measurement session, the illumination of the microscope was adjusted according to the method of Köhler (cited in [28]). Several histograms were produced twice, and they were found to be very similar. From the stained nuclei, 200 nuclei of breast cancer cells were selected, if available. In addition, small lymphocytes were used as internal controls. Laboratory work for measurement of the DNA variables was done at the Department of Pathology, University of Turku, Turku, Finland.

\section{S-phase fraction measurement}

DNA histogram interpretation was applied according to the ESACP consensus report [29]. The S phase fractions (SPF) - a measure of tumor proliferative activity- were automatically calculated by the Ahrens program as the percentage of cells in the $S$ phase of the cycle, and were recorded for all cases. The median SPF value $(11 \%)$ was used as cut off point for distinguishing between tumours with high proliferative activity $(\geq 11 \%)$ and tumours with low proliferative activity $(<11 \%)$, because it provided the best prognosis prediction results in this study.

\section{Ethical consideration}

This study is a part of the breast cancer studies, which have got permission from the local ethical committee of the National Cancer Institute at Sabratha, Libya.

\section{Statistical analysis}

The variables of the material were grouped into logical classes and descriptive statistics calculated for the continuous variables using SPSS 19.0 for Windows (SPSS, Inc., Chicago, USA). Frequency tables were analysed using the Chi-square test, with likelihood ratio (LR), or Fisher's exact test to assess the significance of the correlation between the categorical vari- ables.

For survival analysis, Kaplan- Meier curves were plotted, and differences between the curves analyzed using the log-rank test. Student's t-tests and ANOVA were also used to test differences between the groups.

Multivariate survival analysis for the outcome measure [disease-specific survival (DSS) and disease-free survival (DFS)] was carried out using Cox's proportional hazards model in a backward stepwise manner with the log-likelihood ratio (L-R) significance test, using the default values for enter and exclusion criteria. The assumption of proportional hazards was controlled by log-minus-log (LML) survival plots. In all tests, the values $P<0.05$ were regarded statistically significant.

\section{RESULTS}

\section{General description of the Ki-67 expression and S-phase fraction}

Median Ki-67 expression was $27.5 \%$ (mean $29.6 \%$; range $1 \%-80 \%)$. Ki-67 expression was low $(<10 \%)$ in 24 samples, and high $(\geq 10 \%)$ in 76 samples. Examples of staining are shown in Figure 1. Median SPF was $11.0 \%$ (mean 16.6\%; range 0\%-62\%). S-phase fraction was low $(<11 \%)$ in 44 samples and high $(\geq 11 \%)$ in 56 samples. The Ki-67 expression was more frequent in tumors with high SPF than low SPF $(\mathrm{p}=<.0001)$.

\section{Ki-67 expression and clinicopathological vari- ables}

The significant association between Ki-67 expression $(<10 \%$ versus $\geq 10 \%)$ and clinicopathological variables are shown in Table 2 . High Ki-67 expression was significantly associated with disease recurrence $(p<0.0001)$, hormone receptor negative tumors $(p=$ $0.001)$, advanced stages $(p=0.001)$, poor differentiation of tumors $(p=0.01)$, positive axillary lymph nodes more than three in number $(p=0.01)$ and distant metastasis $(\mathrm{p}=0.01)$.

Age at diagnosis, histological subtypes, tumor size or type of surgery did not have significant relationship with Ki-67.

\section{S-phase fraction and clinicopathological varia- bles}

The associations between SPF at cut point of $11 \%$ with clinicopathological variables are shown in Table 2. High SPF was more frequent in the patients with experienced disease recurrence $(p<0.0001)$, advanced stage $(p<0.0001)$, positive axillary lymph nodes more than three in number $(p<0.0001)$, distant metastasis $(p<0.0001)$ and poor differentiation of tumors $(p=$ 
0.005 ). Young patients ( $<50$ years) tended to have tumors with higher SPF than older patients $(p=0.03)$.

Hormonal status, histological subtypes, tumor

A

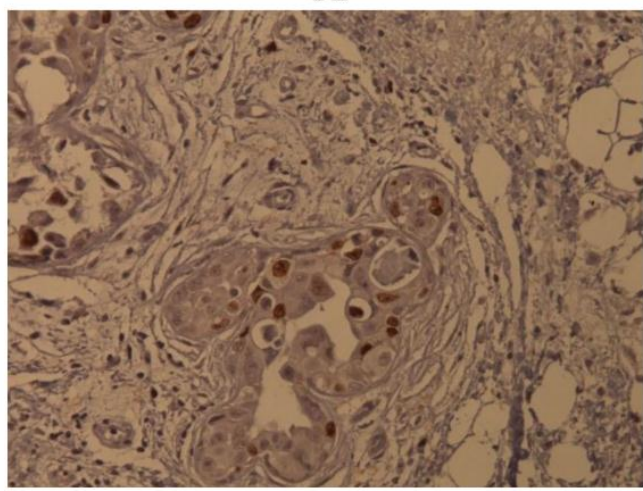

size or treatment did not have significant relationship with SPF level.

B

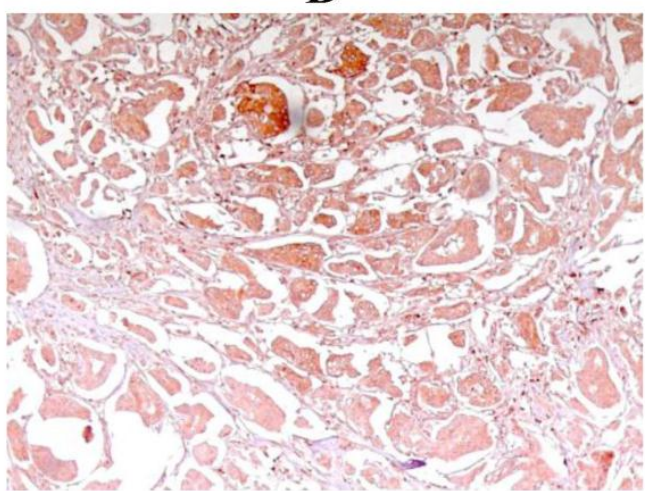

Figure I: Immunohistochemical staining of Ki-67 expression. A: low expression (<10\% nuclear staining). B: high expression ( $\geq 10 \%$ nuclear staining).

Table 2: The association between $\mathrm{Ki}-67$ expression and $\mathrm{S}$ phase fraction with clinicopathological variables in breast cancer $(n=100)$.

\begin{tabular}{|c|c|c|c|c|c|c|c|c|}
\hline \multirow[t]{2}{*}{ Clinicopathological variables } & & \multirow[t]{2}{*}{$\mathrm{N}^{*}$} & \multicolumn{2}{|c|}{ Ki- 67 expression (percent) } & \multirow[t]{2}{*}{$P$ value } & \multicolumn{2}{|c|}{ S-phase fraction value (percent) } & \multirow[t]{2}{*}{$\mathrm{P}$ value } \\
\hline & & & $<10 \%$ & $\geq 10 \%$ & & $<11 \%$ & $\geq 11 \%$ & \\
\hline \multirow[t]{2}{*}{ Age } & $<50$ & 71 & 25.4 & 74.6 & 0.61 & 50.7 & 49.3 & 0.032 \\
\hline & $\geq 50$ & 29 & 20.7 & 79.3 & & 27.6 & 72.4 & \\
\hline \multirow[t]{2}{*}{ Menopausal status } & Premenopausal & 59 & 27.1 & 72.9 & 0.37 & 50.8 & 49.2 & 0.09 \\
\hline & Postmenopausal & 41 & 19.5 & 80.5 & & 34.1 & 65.9 & \\
\hline \multirow[t]{2}{*}{ Hormonal status } & Positive & 67 & 32.8 & 67.2 & 0.001 & 44.7. & 55.3 & 0.16 \\
\hline & Negative & 33 & 6.1 & 93.9 & & 28.6 & 71.4 & \\
\hline \multirow[t]{3}{*}{ Histopathology type } & IDC & 81 & 24.7 & 75.3 & 0.73 & 43.2 & 56.8 & 0.74 \\
\hline & Other types & 19 & 21.1 & 78.9 & & 47.4 & 52.6 & \\
\hline & Grade 1 & 19 & 42.1 & 57.9 & 0.010 & 63.2 & 36.8 & \\
\hline \multirow[t]{3}{*}{ Histological grade } & Grade 2 & 52 & 26.9 & 73.1 & & 48.1 & 52.9 & 0.005 \\
\hline & Grade 3 & 29 & 6.9 & 93.1 & & 20.7 & 79.3 & \\
\hline & Stage 1 & 6 & 83.3 & 16.7 & 0.001 & 83.3 & 18.7 & \\
\hline \multirow[t]{4}{*}{ Clinical stage } & Stage 2 & 27 & 33.3 & 66.7 & & 63.0 & 37.0 & $<0.0001$ \\
\hline & Stage 3 & 57 & 17.5 & 82.5 & & 38.6 & 61.4 & \\
\hline & Stage 4 & 10 & 0.0 & 100.0 & & 0.0 & 100.0 & \\
\hline & $\mathrm{T} 1$ & 4 & 75.0 & 25.0 & 0.053 & 75.0 & 25.0 & \\
\hline \multirow[t]{4}{*}{$\mathrm{T}$} & $\mathrm{T} 2$ & 32 & 31.2 & 68.8 & & 48.7 & 52.3 & 0.05 \\
\hline & $\mathrm{T} 3$ & 41 & 19.5 & 80.5 & & 48.8 & 51.2 & \\
\hline & $\mathrm{T} 4$ & 23 & 13.0 & 87.0 & & 21.7 & 78.3 & \\
\hline & N0 & 18 & 56.7 & 43.3 & 0.025 & 66.7 & 33.3 & \\
\hline \multirow[t]{3}{*}{$\mathrm{N}$} & N1 & 40 & 25.0 & 75.0 & & 60.0 & 40.0 & $<0.0001$ \\
\hline & N2 & 28 & 14.3 & 85.7 & & 21.4 & 78.6 & \\
\hline & N3 & 12 & 8.3 & 91.7 & & 16.7 & 83.3 & \\
\hline \multirow{3}{*}{$\begin{array}{l}\text { Number of positive lymph } \\
\text { nodes }\end{array}$} & $<3$ & 32 & 22.5 & 77.5 & 0.01 & 60.0 & 40.0 & $<0.0001$ \\
\hline & $\geq 3$ & 48 & 12.5 & 87.5 & & 20.0 & 80.0 & \\
\hline & M0 & 90 & 26.7 & 73.3 & 0.016 & 48.9 & 51.1 & \\
\hline Metastases at diagnosis & M1 & 10 & 0.0 & 100.0 & & 0.0 & 100.0 & $<0.0001$ \\
\hline \multirow[t]{2}{*}{ Recurrence (local or distant) } & Yes & 35 & 8.6 & 91.4 & $<0.0001$ & 37.1 & 62.9 & $<0.0001$ \\
\hline & No & 55 & 38.2 & 61.8 & & 56.4 & 43.6 & \\
\hline
\end{tabular}




\section{Ki-67 expression, S-phase fraction and survival outcome}

Univariate survival analysis (survival rates) with Ki-67 expression at cut point of $10 \%$ and SPF value at cut point of $11 \%$ is shown in Table 3 . The survival rate was $64.5 \%$ in patients with low Ki-67 expression ( $\mathrm{p}=$ 0.001 ) and $88.6 \%$ in patients with low SPF values $(\mathrm{p}<0.0001)$. The analysis using Kaplan Meier curves on immunohistochemical Ki-67 and cytometric S-phase fraction indicated that short survival time was associated with high Ki-67 and high SPF.

The association was more significantly associated with SPF than with Ki-67 expressions (Figure 3).
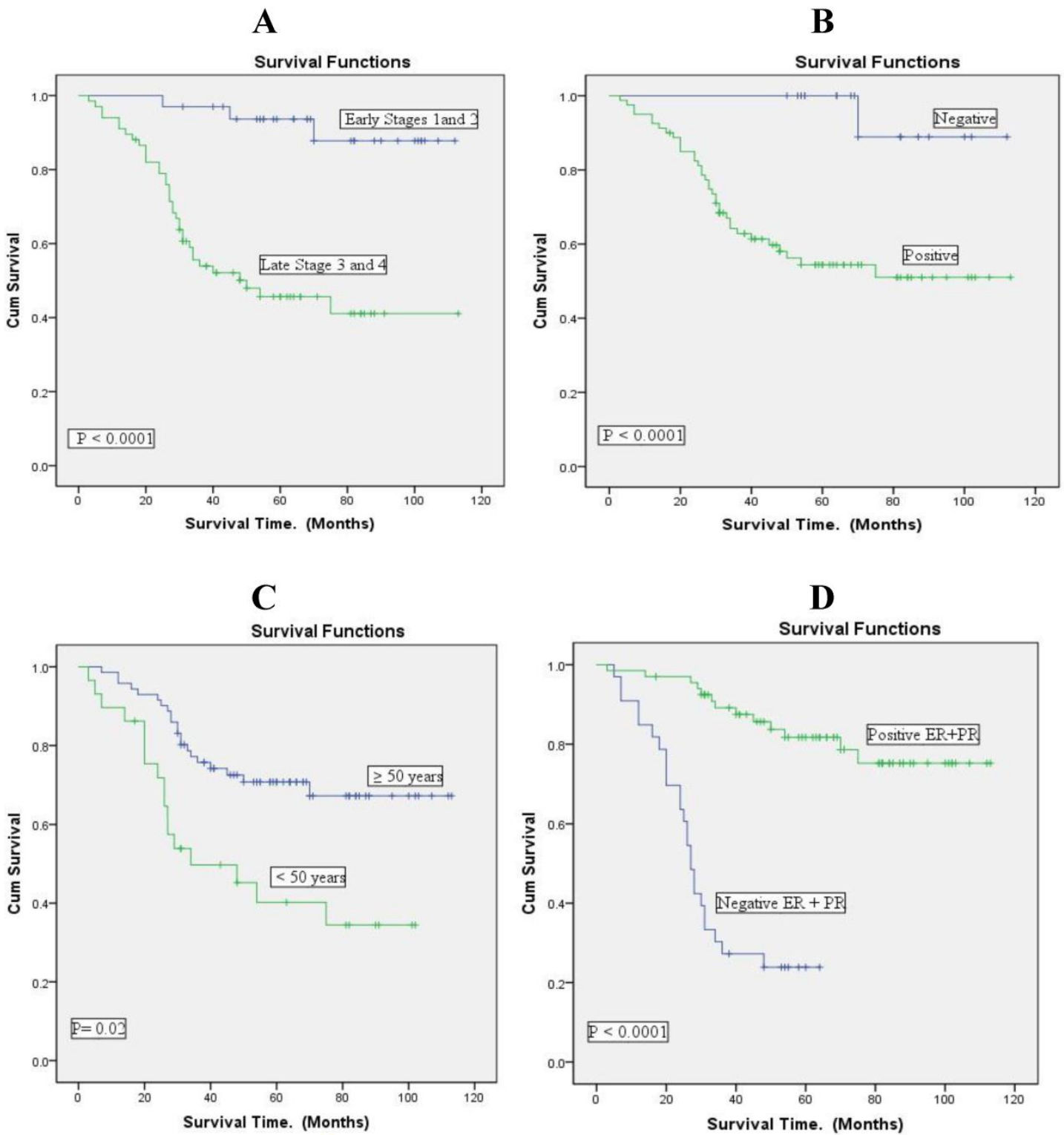

Figure 2: Overall survival according to the clinicopathological variables $(n=100)$ using Kaplan Meier curves. A: clinical stage. B: lymph node status. C: age. D: hormonal receptor status. 

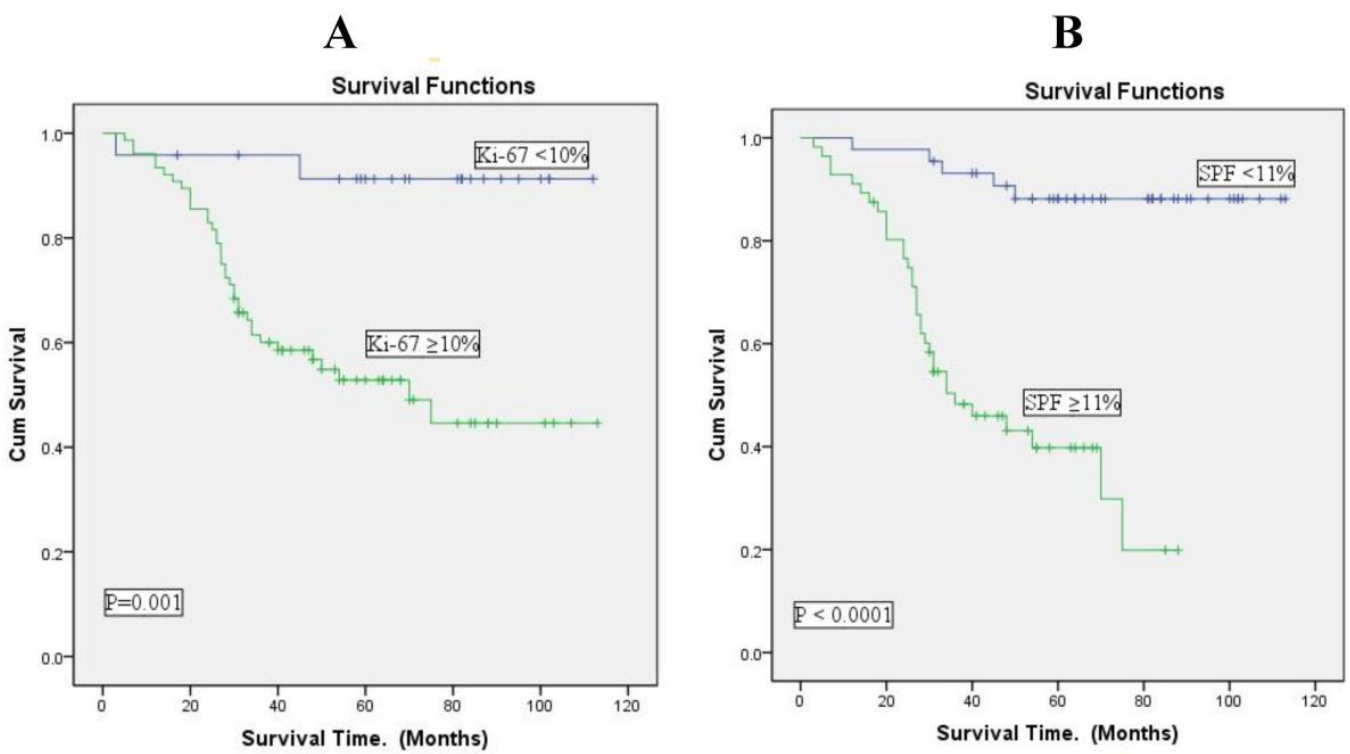

Figure 3: Overall survival according to analysis of Ki-67 expression and S-phase fraction in breast cancer (Kaplan-Meier curves). A: Ki-67 expression at cut point of $10 \%$. B: SPF at cut point of II\%. There is a good separation of the survival curves with both Ki-67 expression and SPF.

Table 3. Univariate survival according to analysis of Ki-67 expression (cut point of $10 \%$ ) and S-phase fraction (cut point of $11 \%)$ in Libyan breast cancer $(n=100)$.

\begin{tabular}{|c|c|c|c|c|c|c|}
\hline \multirow[t]{2}{*}{ Variables } & & \multirow{2}{*}{$\begin{array}{l}\text { Number of } \\
\text { patients }\end{array}$} & \multicolumn{3}{|l|}{ Survival analysis } & \multirow[t]{2}{*}{$\mathrm{P}$-value } \\
\hline & & & $\begin{array}{l}\text { Median survival } \\
\text { (months) }\end{array}$ & $\begin{array}{l}\text { Mean survival } \\
\text { (months) }\end{array}$ & $\begin{array}{l}\text { Survival rate } \\
\text { (percent) }\end{array}$ & \\
\hline All patients & & 100 & 49.00 & 52.9 & 62.0 & \\
\hline \multirow[t]{2}{*}{ Ki-67 expression } & $<10 \%$ & 24 & 75.50 & 70.58 & 64.5 & \multirow[t]{2}{*}{$<0.001$} \\
\hline & $\geq 10 \%$ & 76 & 40.50 & 46.25 & 35.5 & \\
\hline \multirow[t]{2}{*}{ S-Phase fraction } & $<11 \%$ & 44 & 70.00 & 71.07 & 88.6 & \multirow[t]{2}{*}{$<0.0001$} \\
\hline & $\geq 11 \%$ & 56 & 31.00 & 37.18 & 41.1 & \\
\hline
\end{tabular}

\section{S-phase fraction and survival outcome in hormone receptor positive and negative pa- tients}

The analysis using Kaplan Meier curves on cytometric S-phase fraction indicated that short survival time was associated with high SPF in hormone receptor positive and negative patients $(\mathrm{p}=0.004, \mathrm{p}=$ 0.005 , respectively).

The association was more significantly associated with hormone receptor positive patients than with negative patients (Figure 4).

\section{Multivariate Cox Analysis}

Multivariate survival analysis with Ki-67 expression at cut point of $10 \%$ and SPF value at cut point of $11 \%$ is shown in Table 4 and Table 5 . Survival analysis was done according to the Cox model for all breast cancer patients with lymph node status ex- cluded from analysis.

To assess the role of Ki-67 as an independent predictor of DSS and DFS, multivariate Cox regression model was used containing the following prognostic predictors: age, stage, menopausal status and hormonal status.

In this DSS multivariate model, hormonal status $(p=0.001)$, clinical stage $(p=0.001)$ and menopausal status $(p=0.026)$ were independent predictors. For the DFS, the same variables were entered to the model, Ki-67 (cut point $10 \%$ ) proved its borderline significance as the only independent predictor $(p=0.065)$.

To determine the independent prognostic factor with respect to the DSS of patients, SPF (cut point of $11 \%)$ was included in the Cox proportional hazards model, along with the various clinicopathological factors including age, stage, menopausal status, hormonal status, histological grade, and recurrence. 
Multivariate analysis confirmed that higher SPF was an independent factor for poor prognosis $(p=$ $0.007)$ ), which was independently predicted also by hormonal status $(p=0.001)$ and stage $(p=0.005)$. When the same model was used to assess the role of SPF as an independent predictor of DFS, none of the above factors was an independent predictor but all were removed from the model in stepwise backward approach.

Figure 2 shows that in this Libyan material sur- vival is clearly associated with clinical stage, lymph node status and hormone receptor (ER and PR) expression in the neoplasm.

Age is also associated with prognosis, young patients (premenopausal; $<50$ years of age) having worse prognosis. In young patients survival was less than $40 \%$ after 100 months of follow up, but older patients had a survival of almost $70 \%$ at the same stage of follow up.
A

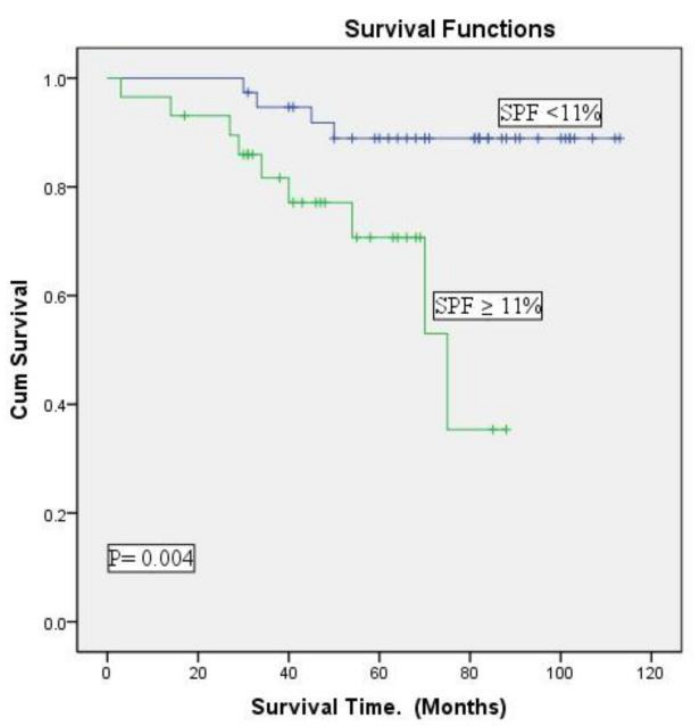

B

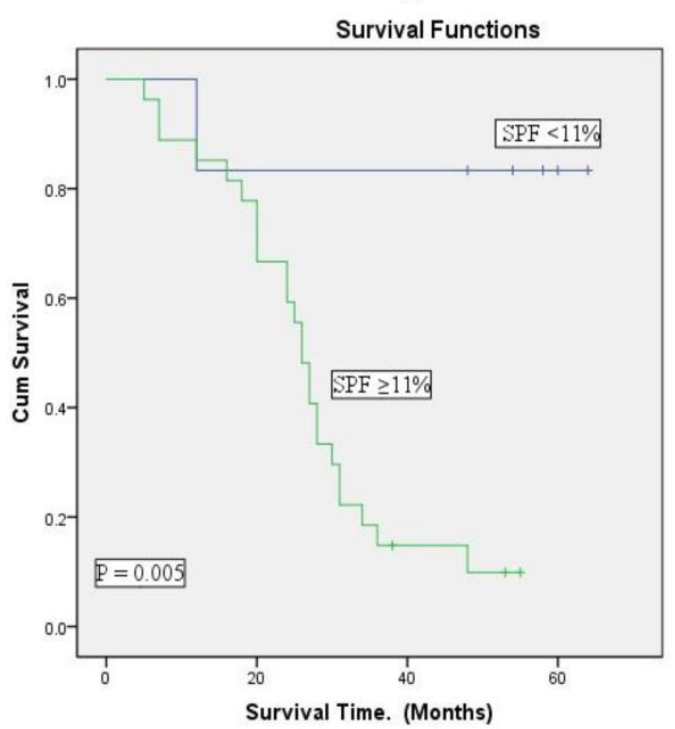

Figure 4: Overall survival according to S-phase fraction (cut point of $1 \mathrm{I} \%$ ) in positive and negative hormone receptor breast cancer patients (Kaplan-Meier curves). A: Hormone receptor positive patients $(n=67)$. B: Hormone receptor negative patients $(n=33)$. There is a good separation of the survival curves with both positive and negative hormonal receptor patients. The hormonal receptor positive patients were the best survival.

Table 4: Multivariate analysis of the factors for disease-specific survival and disease-free survival according to Ki-67 expression (cut point of $10 \%$ in Libyan breast cancer $(n=100)$

\begin{tabular}{|c|c|c|c|c|c|c|}
\hline \multirow[t]{2}{*}{ Variables (category) } & \multicolumn{3}{|c|}{ Disease specific survival model } & \multicolumn{3}{|c|}{ Disease free survival model } \\
\hline & Hazard Ratio (95\% CI) & SE & $\mathrm{P}$ & Hazard Ratio (95\% CI) & SE & $\mathrm{P}$ \\
\hline Age $(>50, \geq 50)$ & $0.762(0.231-2.510)$ & 0.608 & 0.655 & $1.871(0.189-18.488)$ & 1.169 & 0.592 \\
\hline Stage (Low, High) & $11.073(2.624-46.729)$ & 0.735 & 0.001 & $2.421(0.747-7.846)$ & 0.600 & 0.140 \\
\hline Menopausal status (pre, post) & $0.465(0.237-0.915)$ & 0.345 & 0.026 & $1.359(0.430-4.297)$ & 0.587 & 0.602 \\
\hline $\mathrm{Ki}-67(<10 \%, \geq 10 \%)$ & $2.066(0.436-9.786)$ & 0.794 & 0.361 & $4.143(0.918-18.698)$ & 0.769 & 0.065 \\
\hline $\begin{array}{l}\text { Hormonal status (positive, nega- } \\
\text { tive) }\end{array}$ & $0.246(0.111-0.544)$ & 0.406 & 0.001 & $2.544(0.608-10.636)$ & 0.730 & 0.201 \\
\hline
\end{tabular}


Table 5: Multivariate analysis of the factors for disease-specific survival and disease-free survival according to S-phase fraction value (cut point of $11 \%)$ in Libyan breast cancer $(n=100)$

\begin{tabular}{|c|c|c|c|c|c|c|}
\hline \multirow[t]{2}{*}{ Variables (category) } & \multicolumn{3}{|c|}{ Disease specific survival model } & \multicolumn{3}{|c|}{ Disease free survival model } \\
\hline & Hazard Ratio (95\% CI) & SE & $\mathrm{P}$ & Hazard Ratio (95\% CI) & SE & $\mathrm{P}$ \\
\hline Age $(<50, \geq 50)$ & $0.874(0.273-2.793)$ & 0.593 & 0.820 & $1.780(0.179-17.645)$ & 1.170 & 0.622 \\
\hline Stage (Low, High) & $8.192(1.902-35.290)$ & 0.745 & 0.005 & $2.804(0.878-8.953)$ & 0.592 & 0.082 \\
\hline Menopausal status (pre, post) & $0.574(0.291-1.132)$ & 0.347 & 0.109 & $1.348(0.422-4.306)$ & 0.253 & 0.615 \\
\hline S-phase fraction $(<11 \%, \geq 11 \%)$ & $4.029(1.462-11.106)$ & 0.517 & 0.007 & $1.618(0.551-4.748)$ & 0.549 & 0.381 \\
\hline $\begin{array}{l}\text { Hormonal status (positive, nega- } \\
\text { tive) }\end{array}$ & $0.160(0.072-0.356)$ & 0.409 & 0.001 & $1.293(0.266-6.292)$ & 0.807 & 0.750 \\
\hline
\end{tabular}

\section{DISCUSSION}

The clinical course of breast carcinoma is partially unpredictable despite enhanced improvements in diagnoses and therapies. The patient outcome with neoplastic disease in terms of local recurrence, distant metastases and progression, is the major focus of several studies aimed to identifying the most reliable prognostic factors.

At present, prognosis is predicated on the basis of clinicopathological parameters such as tumour size, nodal status, histological type and nuclear grade. Some of these parameters may be influenced by the subjectivity of the pathologist and, therefore, limited in their predictive value [30]. Therefore it is valuable to find prognosticators which can be measured reliably, and can then be used to evaluate patients risk and to choose treatment.

In the present study several interesting and important observations were made, all implicating that the immunostaining analysis of Ki-67 and quantitatively measurable DNA content (which allows the evaluation of SPF) in tumor cells provide significant prognostic information.

Median value of the Ki-67 and SPF were higher than reported data by other studies $[16,19]$. This difference could be due to differences of methodology of techniques, staining and sample preparation, and to variation in the interpretation between centers [31]. It is also suggested that the patients in Libya have aggressive tumor type. Health care aspects are important but biological factors cannot be excluded, either. That African and European breast cancers are different is one of the dominant discussion aspects today.

In this study, confirmed numerous prognostic associations between immunohistochemical KI-67 expression, cytometric S-phase fraction value, clinicopathological variables, and prognosis. Comparisons with European studies are difficult, however, because our material had a greater fraction of advanced cases.
Earlier studies may suggest biological differences because Libyan cancers have the same fraction of hormone positive tumors although they have worse prognosis [5]. Material, however, may be too small for final conclusions.

Anyhow, our study show that high Ki-67 was associated with a higher grade of malignancy such as hormone receptor negative tumors, advanced stages, poor differentiation of tumors, positive axillary lymph nodes, distant metastasis and a high SPF.

High SPF was associated with advanced stages, positive axillary lymph nodes, distant metastasis, poor differentiation of tumors and high Ki-67 expression. High SPF was higher in younger patients than in older.

On other hand low Ki-67 and SPF were more common with favorable prognostic variables. These finding confirm results of other studies [5, 7, 8, 32-34] and these data suggest that patients with a higher Ki-67 expression and SPF value had a worse prognosis.

The SPF showed more significant association with a high grade of malignancy than Ki-67, suggesting that SPF is more useful in assessing prognosis. Gasparini et al [35] compared SPF with some immunohistochemical indicators of cell proliferation, such as Ki-67 and proliferating cell nuclear antigen (PCNA) in breast cancer, and also reported that SPF was superior in assessing prognosis.

Generally, clearly mitosis-associated evaluations (such as SPF and mitotic count) create stronger prognosticators than less directly mitosis-associated factors (e.g. K-67). This is probably due to the fact that a fraction of cells which are proceeding in the cell cycle die through apoptosis before reaching mitosis [36]. Anyhow, apoptosis and mitosis have a positive relationship with each other [37].

Interestingly, also in Libyan breast cancer there is linking of clinicopathological variables, $\mathrm{Ki}-67$, and SPF with the disease outcome, i.e., appearance of recurrence, disease free survival (DFS), and overall survival (OS). 
In current study, Kaplan Meier curves revealed that patients with age $<50$ year, with hormone receptors negative tumors, with advanced stage, and with lymph node involvement had short survival time.

Patients who had tumors with high Ki-67 and high SPF were associated with high rate of disease recurrence, and short survival time. Patients who had tumors with low Ki-67 and low SPF were associated with low rate of disease recurrence, and long survival time.

In addition, we analysed the association between SPF value and patient outcome in hormone receptor positive and negative patients. In this study hormone receptor positive patients with high SPF values had poor survival similar to those of hormone receptor negative patients, suggesting that all patients with hormone receptor positive and negative tumors with high SPF value should be considered to intensive treatment. This was also suggested by Lipponen et al [38], who reported that all women with steroid receptor-negative breast tumours and those receptor-positive tumours with high SPF value should be subjected to postoperative adjuvant chemotherapy immediately.

In contrast, a particularly good prognosis was observed among hormone receptor positive and negative patients with low SPF values, suggesting that the need for additional therapy is questionable in hormone receptor positive patients with low SPF value.

Univariate survival analysis showed that SPF was more statistically significant than Ki-67 for survival time. This findings are in agreement with results of other studies[17-20, 35].These data also suggest that patients with a higher Ki-67 expression and SPF value have a worse prognosis and SPF more useful proliferation maker to assess tumor prognosis.

Cox regression analysis showed that Ki-67 was of borderline significance as an independent predictor for DFS. SPF was an independent factor for DSS with hormonal status and clinical stage. The same finding was also reported by Dettmar et al, who showed by multivariate analysis that SPF has the highest prognostic value [39].

In fact, this is the first study to compare between immunohistochemical Ki-67 expression and cytometric S-phase fraction in the Libyan breast cancer. The results suggest that SPF showed more significant association with a high grade of malignancy than Ki-67.

In addition survival analysis results also suggest that SPF was superior in assessing prognosis.

In conclusion, the Ki-67 index had wide distribution of $1-80 \%$, and the median was $27.5 \%$. While SPF value had distribution of $1-62 \%$, and the median was $11 \%$ of primary breast cancer in Libyans. Patients with high Ki-67 and SPF were a significantly associated with a high grade of malignancy, with poorer prognosis and with increased rate of recurrence. On the other hand, patients who had tumors with low Ki-67 and SPF had a favorable prognosis and low risk of recurrence.

SPF is more useful proliferation cell marker to assess tumor prognosis.

These markers may reflect the aggressive behavior of Libyan breast cancer and predict of the recurrence. It is therefore important to take these markers into consideration in selecting patients for the high risk subgroup for intensive treatment.

\section{Acknowledgements}

The authors acknowledge the Libyan Health Ministry for financing the visit of Dr Ermiah to the Departments of Pathology and Oncology, University of Turku, and Turku University Hospital, Finland for applying laboratory work in this research. We also wish to thank the National Oncology Institute, Sabratha, Libya for support in collecting the data and providing the research facilities.

\section{Competing Interests}

The authors have declared that no competing interest exists.

\section{References}

1. Abussa A. Hospital cancer registry annual report 2006. Sabratha, Libya: African Oncology Institute. 2007: 18-20.

2. El Mistiri M, Verdecchia A, Rashid I, El Sahli N, El Mangush M, Federico $\mathrm{M}$. Cancer incidence in eastern Libya: the first report from the Benghazi Cancer Registry, 2003. International journal of cancer Journal international du cancer. 2007; 120: 392-7. doi:10.1002/ijc.22273.

3. Abulkhair O, Saghir N, Sedky L, Saadedin A, Elzahwary H, Siddiqui N, et al. Modification and implementation of NCCN guidelines on breast cancer in the Middle East and North Africa region. J Natl Compr Canc Netw. 2010; 8 Suppl 3: S8-S15.

4. Stapleton JM, Mullan PB, Dey S, Hablas A, Gaafar R, Seifeldin IA, et al. Patient-mediated factors predicting early- and late-stage presentation of breast cancer in Egypt. Psycho-oncology. 2011; 20: 532-7. doi:10.1002/pon.1767.

5. Boder J, Abdalla F, Elfageih M, Abusaa A, Alfagieh M, Buhmeida A, et al. Breast cancer patients in Libya: Comparison with European and central African patients. Oncology Letters. 2011; 2: 323-30.

6. Galizia G, Orditura M, Romano C, Lieto E, Castellano P, Pelosio L, et al. Prognostic significance of circulating IL-10 and IL-6 serum levels in colon cancer patients undergoing surgery. Clinical immunology (Orlando, Fla). 2002; 102: 169-78. doi:10.1006/clim.2001.5163.

7. Yerushalmi R, Woods R, Ravdin PM, Hayes MM, Gelmon KA. Ki67 in breast cancer: prognostic and predictive potential. Lancet Oncol. 2010; 11: 174-83. doi:10.1016/s1470-2045(09)70262-1.

8. Urruticoechea A, Smith IE, Dowsett M. Proliferation marker Ki-67 in early breast cancer. J Clin Oncol. 2005; 23: 7212-20. doi:10.1200/jco.2005.07.501.

9. Collan YU, Eskelinen MJ, Nordling SA, Lipponen P, Pesonen E, Kumpusalo LM, et al. Prognostic studies in breast cancer. Multivariate combination of nodal status, proliferation index, tumor size, and DNA ploidy. Acta Oncol. 1994; 33: 873-8.

10. Friedrich K, Scheithauer J, Dimmer V, Meyer W, Theissig F, Haroske G, et al. DNA ploidy and chromosomal imbalances in invasive ductal breast 
cancer. A comparative study of DNA image cytometry and comparative genomic hybridization (CGH). Anal Cell Pathol. 2000; 20: 69-82.

11. Yildirim-Assaf S, Coumbos A, Hopfenmuller W, Foss HD, Stein H, Kuhn $\mathrm{W}$. The prognostic significance of determining DNA content in breast cancer by DNA image cytometry: the role of high grade aneuploidy in node negative breast cancer. J Clin Pathol. 2007; 60: 649-55. doi:10.1136/jcp.2005.035550.

12. Wintzer HO, Zipfel I, Schulte-Monting J, Hellerich U, von Kleist S. Ki-67 immunostaining in human breast tumors and its relationship to prognosis. Cancer. 1991; 67: 421-8.

13. Tubiana M, Pejovic MH, Chavaudra N, Contesso G, Malaise EP. The long-term prognostic significance of the thymidine labelling index in breast cancer. International journal of cancer Journal international du cancer. 1984; 33: 441-5.

14. Cooper LS, Gillett CE, Smith P, Fentiman IS, Barnes DM. Cell proliferation measured by MIB1 and timing of surgery for breast cancer. Br J Cancer. 1998; 77: 1502-7.

15. Gerdes J, Li L, Schlueter C, Duchrow M, Wohlenberg C, Gerlach C, et al. Immunobiochemical and molecular biologic characterization of the cell proliferation-associated nuclear antigen that is defined by monoclonal antibody Ki-67. Am J Pathol. 1991; 138: 867-73.

16. Railo M, Nordling S, von Boguslawsky K, Leivonen M, Kyllonen L, von Smitten K. Prognostic value of Ki-67 immunolabelling in primary operable breast cancer. Br J Cancer. 1993; 68: 579-83.

17. Brown DC, Gatter KC. Ki67 protein: the immaculate deception? Histopathology. 2002; 40: 2-11.

18. Goodson WH, 3rd, Moore DH, 2nd, Ljung BM, Chew K, Mayall B, Smith HS, et al. The prognostic value of proliferation indices: a study with in vivo bromodeoxyuridine and Ki-67. Breast Cancer Res Treat. 2000; 59: 113-23.

19. Zhang S, Yuan $Y$, Wang X. [Prognosis prediction of S-phase fraction and p53, c-erbB-2, estrogen receptor, progesterone receptor in axillary node-negative breast cancer]. Zhonghua Wai Ke Za Zhi. 1997; 35: 475-7.

20. Michels JJ, Duigou F, Marnay J. Flow cytometry in primary breast carcinomas. Prognostic impact of proliferative activity. Breast Cancer Res Treat. 2000; 62: 117-26.

21. Jansen RL, Hupperets PS, Arends JW, Joosten-Achjanie SR, Volovics A, Schouten HC, et al. MIB-1 labelling index is an independent prognostic marker in primary breast cancer. Br J Cancer. 1998; 78: 460-5.

22. [Internet] AJCC. 5th Edition AJCC Cancer Staging Manual; LippincottRaven. 1999. http://www.cancerstaging.org/products/csmanual5ed. pdf.

23. Allred DC, Harvey JM, Berardo M, Clark GM. Prognostic and predictive factors in breast cancer by immunohistochemical analysis. Mod Pathol. 1998; 11: 155-68.

24. Molino A, Micciolo R, Turazza M, Bonetti F, Piubello Q, Bonetti A, et al. Ki-67 immunostaining in 322 primary breast cancers: associations with clinical and pathological variables and prognosis. International journal of cancer Journal international du cancer. 1997; 74: 433-7.

25. Pinto AE, Andre S, Pereira T, Nobrega S, Soares J. Prognostic comparative study of S-phase fraction and $\mathrm{Ki}-67$ index in breast carcinoma. J Clin Pathol. 2001; 54: 543-9.

26. Hedley DW, Friedlander ML, Taylor IW. Application of DNA flow cytometry to paraffin-embedded archival material for the study of aneuploidy and its clinical significance. Cytometry. 1985; 6: 327-33.

27. Gaub I, Auer G, Zetterberg A. Quantitative cytochemical aspects of a combined feulgen-naphthol yellow $\mathrm{S}$ staining procedure for the simultaneous determination of nuclear and cytoplasmic proteins and DNA in mammalian cells. Exp Cell Res. 1975; 92: 323-32.

28. Bohnhoff GL. Setting up proper illumination on your microscope. Am J Med Technol. 1979; 45: 650-1.

29. Haroske G, Giroud F, Reith A, Bocking A. 1997 ESACP consensus report on diagnostic DNA image cytometry. Part I: basic considerations and recommendations for preparation, measurement and interpretation. European Society for Analytical Cellular Pathology. Anal Cell Pathol. 1998; 17: 189-200

30. Visscher DW, Zarbo RJ, Greenawald KA, Crissman JD. Prognostic significance of morphological parameters and flow cytometric DNA analysis in carcinoma of the breast. Pathol Annu. 1990; 25 (Pt 1): 171-210.

31. Leivonen M, Krogerus L, Nordling S. DNA analysis in advanced breast cancer. Cancer Detect Prev. 1994; 18: 87-96.

32. Wenger CR, Beardslee S, Owens MA, Pounds G, Oldaker T, Vendely P, et al. DNA ploidy, S-phase, and steroid receptors in more than 127,000 breast cancer patients. Breast Cancer Res Treat. 1993; 28: 9-20.

33. Nishimura R, Osako T, Okumura Y, Hayashi M, Arima N. Clinical significance of $\mathrm{Ki}-67$ in neoadjuvant chemotherapy for primary breast cancer as a predictor for chemosensitivity and for prognosis. Breast Cancer. 2010; 17: 269-75. doi:10.1007/s12282-009-0161-5.

34. Brown RW, Allred CD, Clark GM, Osborne CK, Hilsenbeck SG. Prognostic value of $\mathrm{Ki}-67$ compared to S-phase fraction in axillary node-negative breast cancer. Clin Cancer Res. 1996; 2: 585-92.

35. Gasparini G, Boracchi P, Verderio P, Bevilacqua P. Cell kinetics in human breast cancer: comparison between the prognostic value of the cytofluorimetric S-phase fraction and that of the antibodies to Ki-67 and PCNA antigens detected by immunocytochemistry. International journal of cancer Journal international du cancer. 1994; 57: 822-9.

36. Jalava P, Kuopio T, Juntti-Patinen L, Kotkansalo T, Kronqvist P, Collan Y. Ki67 immunohistochemistry: a valuable marker in prognostication but with a risk of misclassification: proliferation subgroups formed based on Ki67 immunoreactivity and standardized mitotic index. Histopathology. 2006; 48: 674-82. doi:10.1111/j.1365-2559.2006.02402.x.

37. Huovinen R, Warri A, Collan Y. Mitotic activity, apoptosis and TRPM-2 mRNA expression in DMBA-induced rat mammary carcinoma treated with anti-estrogen toremifene. International journal of cancer Journal international du cancer. 1993; 55: 685-91.

38. Lipponen P, Eskelinen M, Papinaho S, Klemi PJ, Aaltomaa S, Kosma VM, et al. Sex steroid receptors, S-phase fraction and DNA ploidy as determinants of the risk of relapse and death of female breast cancer. Anticancer research. 1992; 12: 677-82.

39. Dettmar P, Harbeck N, Thomssen C, Pache L, Ziffer P, Fizi K, et al. Prognostic impact of proliferation-associated factors MIB1 (Ki-67) and S-phase in node-negative breast cancer. Br J Cancer. 1997; 75: 1525-33 